\title{
THE EFFECTS OF SECTORAL AND TECHNOLOGICAL CHANGES ON THE SKILL COMPOSITION OF EMPLOYMENT IN THE UNITED KINGDOM 1951-91.
}

\author{
Martin Hoskins * \\ Public Sector Economics Research Centre \\ Department of Economics, University of Leicester, U.K.
}

Revised January 2000

\begin{abstract}
This paper presents quantitative estimates of the effects of technological change and changes in sectoral employment on skill composition in the United Kingdom for six skill groups, in each decade 1951 - 1991, for men and women separately.
\end{abstract}

Keywords: Skill change, United Kingdom, technological change, sectoral composition.

JEL classification: J40, O52.

Address for correspondence: M.D.Hoskins, Department of Economics, University of Leicester, University Road, Leicester LE17RH, United Kingdom. Fax: + 44 (0)116 2525129 Tel: +44 (0)116 2522904 Email: mdh@le.ac.uk

* I am grateful to participants at the PSERC research workshop for helpful comments and to Steve Pudney and an anonymous referee for advice which has improved the paper enormously. 


\section{Introduction}

A widening disparity in the economic fortunes of workers with different educational and skill attainments has been observed in many countries. This has been attributed to bias in technological changes and changes in the sectoral balance of employment.

Changes in sectoral composition have themselves been linked to changes in trade patterns, and particularly to recent changes in trade patterns with economies in SouthEast Asia. . In 1951, the U.K. had over 40\% of employment in manufacturing and over $25 \%$ of G.D.P. involved in foreign trade. These were some of the highest proportions in the world and left the U.K. very open to changes in the world economy. Sectoral change resulted in a fall in manufacturing employment to $22 \%$ by 1991 . This note assesses the effects of sectoral and technological changes on skill composition in the United Kingdom.

We present quantitative estimates of the relative importance of changes in sectoral composition and technology for each decade from 1951-91, showing how long-standing the different effects are and how their relative importance has varied. The estimates are given for 6 occupational classes, distinguishing three skill levels within the non-manual (white-collar) and manual (production) categories. Separate estimates are given for male and female workers as well as totals. The estimates are derived from changes across the whole economy including services as well as manufacturing.

\section{Data and methods}

The data are from published tables from the U.K. decennial census. These provide information on employment by sex by six social classes for a large number of industries, services and utilities. These have been aggregated into a consistent panel of 46 sectors, detailed in Table 1. 
Table 1 Industrial sectors and their employment shares

\begin{tabular}{l|cc|l|ll|l|lc}
\hline \multicolumn{1}{c|}{ Sector } & \multicolumn{2}{|c|}{ Employment share } & & \multicolumn{2}{|c|}{ Employment share } & \multicolumn{1}{l}{ Sector } & \\
\hline & 1951 & 1991 & & 1951 & 1991 & & 1951 & 1991 \\
\hline Ag \& Hort & $4.62 \%$ & $1.84 \%$ & MotorVhcls & $1.94 \%$ & $1.05 \%$ & Rail & $2.35 \%$ & $0.54 \%$ \\
Forestry & $0.11 \%$ & $0.06 \%$ & OtrTransEq & $2.32 \%$ & $0.96 \%$ & OtrInlndTr & $2.30 \%$ & $2.34 \%$ \\
Fishing & $0.11 \%$ & $0.07 \%$ & Instr Engng & $0.53 \%$ & $0.38 \%$ & SeaTran & $1.02 \%$ & $0.17 \%$ \\
Coal & $3.39 \%$ & $0.36 \%$ & FoodDrTob & $3.20 \%$ & $2.26 \%$ & AirTran & $0.12 \%$ & $0.32 \%$ \\
Coke & $0.07 \%$ & $0.00 \%$ & Textiles & $3.25 \%$ & $0.75 \%$ & MiscTran & $0.39 \%$ & $1.09 \%$ \\
Min Procs & $0.23 \%$ & $0.08 \%$ & LthrFurGds & $0.31 \%$ & $0.07 \%$ & PostCmmcn & $1.59 \%$ & $2.02 \%$ \\
Elec \& Gas & $1.50 \%$ & $0.94 \%$ & FootClthg & $4.18 \%$ & $1.20 \%$ & BusnsServc & $1.33 \%$ & $11.5 \%$ \\
Water & $0.17 \%$ & $0.26 \%$ & Timber & $1.51 \%$ & $1.23 \%$ & PubAdmin & $5.24 \%$ & $6.03 \%$ \\
Metl Manuf & $4.29 \%$ & $0.57 \%$ & PapPrntng & $5.76 \%$ & $2.09 \%$ & Education & $2.33 \%$ & $6.35 \%$ \\
Ext Min nes & $0.32 \%$ & $0.37 \%$ & RubPlastc & $0.52 \%$ & $0.85 \%$ & MedHealth & $2.84 \%$ & $6.26 \%$ \\
MfNonMtl & $1.38 \%$ & $0.79 \%$ & OthrManf & $0.75 \%$ & $0.34 \%$ & OtrServcs & $0.38 \%$ & $5.68 \%$ \\
Chemicals & $1.81 \%$ & $1.33 \%$ & Constrn & $6.20 \%$ & $7.51 \%$ & RecrecServc & $0.99 \%$ & $2.34 \%$ \\
ManmdFibr & $0.47 \%$ & $0.02 \%$ & Wholesale & $3.48 \%$ & $4.53 \%$ & PersnlServc & $1.71 \%$ & $1.32 \%$ \\
MetPdc nes & $2.32 \%$ & $1.26 \%$ & Retail & $8.56 \%$ & $10.8 \%$ & DmstcServc & $2.45 \%$ & $0.29 \%$ \\
Mec Engng & $4.10 \%$ & $3.07 \%$ & HotelCtrng & $3.55 \%$ & $4.69 \%$ & & & \\
Elec Engng & $2.67 \%$ & $2.61 \%$ & Repair & $1.33 \%$ & $1.38 \%$ & & & \\
\hline
\end{tabular}

We identify six occupational classes, listed in Table 2, using a classification which has been subject to only minor change.

Table 2 Occupational categories and employment shares

\begin{tabular}{ll|c|c}
\hline \multicolumn{1}{c|}{ Occupational class } & 1951 share & 1991 share \\
\hline I & Professionals & $2 \%$ & $5 \%$ \\
II & Managers & $14 \%$ & $29 \%$ \\
III(N) & Skilled non-manuals & $18 \%$ & $24 \%$ \\
III(M) & Skilled manuals & $35 \%$ & $21 \%$ \\
IV & Partly-skilled manual & $20 \%$ & $16 \%$ \\
V & Unskilled & $11 \%$ & $6 \%$ \\
\hline
\end{tabular}

Since employment by occupation varies considerably across sectors, changes in the occupational composition of employment are due to sectoral change as well as changes within sectors resulting from biased technological change. Define $\mathbf{e}_{t}$ as the row vector of industry/service employment proportions in any year $t$ and $\mathbf{T}_{t}$ the matrix 
of employment proportions by occupation within sectors. For an economy of a standard size total changes may be decomposed as follows:

$$
\begin{aligned}
\mathbf{e}_{2} \mathbf{T}_{2}-\mathbf{e}_{1} \mathbf{T}_{1} & =\mathbf{e}_{2}\left(\mathbf{T}_{2}-\mathbf{T}_{1}\right)+\left(\mathbf{e}_{2}-\mathbf{e}_{1}\right) \mathbf{T}_{1} \\
& =\mathbf{e}_{1}\left(\mathbf{T}_{2}-\mathbf{T}_{1}\right)+\left(\mathbf{e}_{2}-\mathbf{e}_{1}\right) \mathbf{T}_{2}
\end{aligned}
$$

Here the term $\left(\mathbf{T}_{2}-\mathbf{T}_{1}\right)$ gives the technological change effect, weighted by terminal or base year employment, and the term $\left(\mathbf{e}_{2}-\mathbf{e}_{1}\right)$ gives the sectoral change effect, weighted either by initial or terminal year technology. The two forms of the decomposition are equally valid and may give different results. However, apart from the professional and unskilled categories, which are small and sensitive to small changes, both decompositions generally present a similar picture. Results are presented in Tables 3-5 which give percentage changes over each decade and the relative shares of these changes attributable to technology and sector effects.

\section{Males and females together}

For the professional category, industry effects are consistently positive in all subperiods and stronger than technology effects. There is some inconsistency in the measures produced by the two decompositions. For the managerial group, except for the decade 1951-61 both industry and technology effects are positive with technology effects dominating and becoming stronger. Industry effects however are important.

For skilled white-collar workers, industry effects are consistently positive but technology effects consistently negative after 1961, becoming weaker after 1971.This contrasts with the managerial group and shows the importance of distinguishing skill levels among non-manual workers. For skilled manual workers, industry effects are consistently negative and stronger than the technology effects, which are consistently negative after 1971. For the partly skilled group, the results are similar but with 
stronger negative technology effects after 1971. Finally, the unskilled group has suffered most, with very strong and increasing negative technology effects.

\section{Males and females separately}

There is a general consistency in the results for males and females in occupational classes II-IV, which account for over $85 \%$ of male and female employment in all periods. For managers, technology effects are positive since 1961, stronger than industry effects for men in all periods and also for women except the decade 1971-81, but vary in their intensity, having their greatest effect in 1971-81 for men and 1961-71 for women. For skilled non-manuals, technology effects are consistently negative and have their greatest impact in 1961-71 for both males and females. From 1961 onwards technological changes cause a clear switch towards the more highly skilled managerial group among non-manual workers. For skilled and partly skilled manual workers, technology and industry effects are negative for both men and women after 1971 . Industry effects are more important for females than males. Technological effects accelerate in the decade 1981-91 in reducing the employment of manual women. Technology effects are strongly negative for unskilled men in all periods and for unskilled women after 1981. 
Table 3 Decomposition of employment changes by occupation: males + females.

\begin{tabular}{|c|c|c|c|c|c|c|}
\hline & I & II & III(N) & III(M) & IV & $\mathbf{V}$ \\
\hline \multicolumn{7}{|c|}{1951 - 1991} \\
\hline Total change \% & 156.3 & 103.1 & 32.6 & -39.9 & -21.8 & -47.0 \\
\hline Technology share 1 & -161.9 & 54.0 & -2.2 & -8.1 & 12.3 & -34.3 \\
\hline Technology share 2 & 77.0 & 62.5 & 1.6 & -16.9 & 2.5 & -47.8 \\
\hline Sectoral share 1 & 318.2 & 49. 1 & 34.9 & -31.8 & -34.1 & -12.7 \\
\hline Sectoral share 2 & 79.3 & 40.5 & 31.1 & -23.1 & -24.3 & 0.8 \\
\hline \multicolumn{7}{|c|}{1981 - 1991} \\
\hline Total change \% & 20.8 & 25.8 & 5.6 & -15.4 & -15.9 & -18.0 \\
\hline Technology share 1 & 9.9 & 21.8 & -3.7 & -6.0 & -9.1 & -19.3 \\
\hline Technology share 2 & 13.1 & 21.6 & -3.4 & -6.5 & -8.6 & -20.8 \\
\hline Sectoral share 1 & 10.9 & 4.1 & 9.4 & -9.3 & -6.8 & 1.3 \\
\hline Sectoral share & 7.7 & 4.4 & 9.0 & -8.8 & -7.3 & 2.9 \\
\hline \multicolumn{7}{|c|}{$1971-1981$} \\
\hline Total change \% & 9.6 & 30.0 & 3.4 & -12.9 & -10.4 & -7.4 \\
\hline Technology share 1 & -1.7 & 19.4 & -3.3 & -2.1 & -7.3 & -7.0 \\
\hline Technology share 2 & 2.3 & 20.2 & -2.0 & -3.0 & -5.8 & -15.1 \\
\hline Sectoral share & 11.3 & 10.7 & 6.7 & -10.8 & -3.1 & -0.4 \\
\hline Sectoral share & 7.3 & 9.9 & 5.3 & -9.9 & -4.5 & 7.6 \\
\hline \multicolumn{7}{|c|}{$1961-1971$} \\
\hline Total change \% & 25.4 & 23.4 & -20.1 & -1.6 & 12.5 & -5.9 \\
\hline Technology share 1 & 5.3 & 15.7 & -24.4 & 4.3 & 20.1 & -8.8 \\
\hline Technology share 2 & 10.9 & 12.6 & -22.2 & 5.6 & 15.6 & -7.3 \\
\hline Sectoral share 1 & 20.1 & 7.7 & 4.3 & -5.9 & -7.6 & 2.9 \\
\hline Sectoral share & 14.5 & 10.8 & 2.1 & -7.2 & -3.1 & 1.4 \\
\hline \multicolumn{7}{|c|}{$1951-1961$} \\
\hline Total change \% & 54.4 & 0.6 & 52.0 & -17.2 & -7.8 & -25.8 \\
\hline Technology share 1 & -30.3 & -13.1 & 43.3 & -10.3 & 6.2 & -26.5 \\
\hline Technology share 2 & 21.6 & -6.1 & 42.4 & -12.2 & 0.1 & -25.9 \\
\hline Sectoral share 1 & 84.7 & 13.6 & 8.7 & -6.9 & -14.0 & 0.7 \\
\hline Sectoral share & 32.8 & 6.6 & 9.6 & -5.0 & -7.9 & 0.1 \\
\hline
\end{tabular}


Table 4 Decomposition of employment changes by occupation: males

\begin{tabular}{|c|c|c|c|c|c|c|}
\hline & I & II & III(N) & III(M) & IV & $\mathbf{V}$ \\
\hline \multicolumn{7}{|c|}{1951 - 1991} \\
\hline Total change $\%$ & 205.4 & 112.9 & 0.9 & -23.6 & -17.0 & -61.9 \\
\hline Technology share 1 & -45.8 & 70.7 & -26.5 & -5.7 & 18.7 & -54.2 \\
\hline Technology share 2 & 99.6 & 83.1 & -17.9 & -9.9 & 1.2 & -64.4 \\
\hline Sectoral share & 251.2 & 42.2 & 27.4 & -17.9 & -35.7 & -7.7 \\
\hline Sectoral share & 105.8 & 29.8 & 18.7 & -13.7 & -18.2 & 2.5 \\
\hline
\end{tabular}

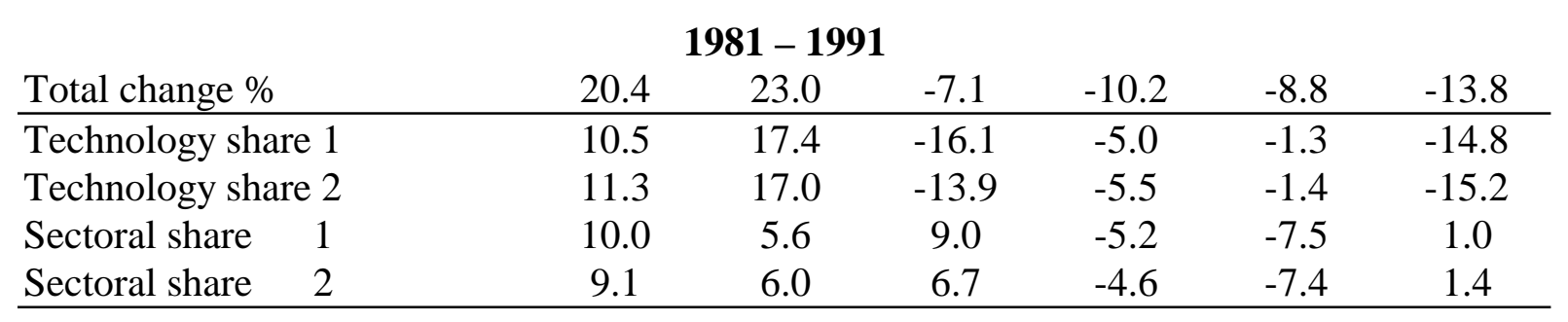

\begin{tabular}{|c|c|c|c|c|c|c|}
\hline \multirow[b]{2}{*}{ Total change \% } & \multicolumn{3}{|c|}{$1971-1981$} & \multirow[b]{2}{*}{-8.1} & \multirow[b]{2}{*}{-7.0} & \multirow[b]{2}{*}{-28.7} \\
\hline & 13.9 & 30.6 & 2.0 & & & \\
\hline Technology share 1 & 0.9 & 22.9 & -6.7 & -2.2 & -3.5 & -25.6 \\
\hline Technology share 2 & 4.9 & 22.7 & -5.2 & -2.8 & -2.2 & -30.9 \\
\hline Sectoral share & 13.1 & 7.8 & 8.7 & -5.9 & -3.5 & -3.1 \\
\hline Sectoral share & 9.0 & 7.9 & 7.1 & -5.4 & -4.8 & 2.3 \\
\hline
\end{tabular}

\begin{tabular}{|c|c|c|c|c|c|c|}
\hline \multicolumn{7}{|c|}{$1961-1971$} \\
\hline Total change \% & 34.5 & 12.1 & -20.2 & 3.2 & -2.7 & -12.0 \\
\hline Technology share 1 & 24.3 & 9.4 & -24.2 & 3.7 & 4.5 & -12.6 \\
\hline Technology share 2 & 23.7 & 10.6 & -22.5 & 5.4 & -2.1 & -11.1 \\
\hline Sectoral share & 10.2 & 2.7 & 4.0 & -0.5 & -7.2 & 0.6 \\
\hline Sectoral share & 10.8 & 1.5 & 2.4 & -2.2 & -0.6 & -0.9 \\
\hline
\end{tabular}

\begin{tabular}{|c|c|c|c|c|c|c|}
\hline \multicolumn{7}{|c|}{1951 - 1961} \\
\hline Total change \% & 65.4 & 18.2 & 33.4 & -10.3 & 0.6 & -29.6 \\
\hline Technology share 1 & -16.3 & 5.7 & 27.1 & -4.2 & 12.6 & -32.3 \\
\hline Technology share 2 & 22.1 & 14.4 & 22.1 & -5.4 & 4.8 & -29.3 \\
\hline Sectoral share & 81.7 & 12.5 & 6.4 & -6.1 & -12.0 & 2.6 \\
\hline Sectoral share & 43.3 & 3.8 & 11.4 & -4.9 & -4.2 & -0.3 \\
\hline
\end{tabular}


Table 5 Decomposition of employment changes by occupation: females

\begin{tabular}{|c|c|c|c|c|c|c|}
\hline & I & II & III(N) & III(M) & IV & $\mathbf{V}$ \\
\hline \multicolumn{7}{|c|}{$1951-1991$} \\
\hline Total change $\%$ & 142.4 & 85.3 & 17.1 & -61.0 & -32.9 & -10.7 \\
\hline Technology share 1 & -410.4 & 33.8 & -10.6 & -1.7 & 7.9 & 0.0 \\
\hline Technology share 2 & 47.6 & 30.7 & -2.9 & -31.9 & 6.0 & 2.3 \\
\hline Sectoral share & 552.8 & 51.5 & 27.6 & -59.3 & -40.8 & -10.8 \\
\hline Sectoral share & 94.9 & 54.6 & 20.0 & -29.1 & -38.9 & -13.0 \\
\hline
\end{tabular}

\begin{tabular}{|c|c|c|c|c|c|c|}
\hline \multicolumn{7}{|c|}{1981 - 1991} \\
\hline Total change \% & 79.1 & 31.0 & 3.8 & -15.7 & -24.6 & -24.5 \\
\hline Technology share 1 & 65.5 & 32.4 & -4.1 & -5.5 & -17.1 & -20.9 \\
\hline Technology share 2 & 67.5 & 32.1 & -3.3 & -5.5 & -16.3 & -25.3 \\
\hline Sectoral share & 13.6 & -1.4 & 7.9 & -10.2 & -7.5 & -3.6 \\
\hline Sectoral share & 11.6 & -1.1 & 7.1 & -10.2 & -8.2 & 0.9 \\
\hline
\end{tabular}

\begin{tabular}{|c|c|c|c|c|c|c|}
\hline \multicolumn{7}{|c|}{$1971-1981$} \\
\hline Total change \% & 8.0 & 29.9 & -0.9 & -22.6 & -15.8 & 22.6 \\
\hline Technology share 1 & -2.3 & 10.5 & -2.3 & 3.0 & -11.0 & 20.9 \\
\hline Technology share 2 & -6.7 & 13.2 & 0.7 & -4.4 & -9.7 & 7.2 \\
\hline Sectoral share 1 & 10.3 & 19.4 & 1.3 & -25.6 & -4.8 & 1.7 \\
\hline Sectoral share & 14.7 & 16.7 & -1.6 & -18.2 & -6.1 & 15.5 \\
\hline
\end{tabular}

\begin{tabular}{|c|c|c|c|c|c|c|c|}
\hline \multirow{2}{*}{\multicolumn{2}{|c|}{ Total change \% }} & \multicolumn{3}{|c|}{$1961-1971$} & \multirow[b]{2}{*}{1.9} & \multirow[b]{2}{*}{36.7} & \multirow[b]{2}{*}{8.2} \\
\hline & & 12.4 & 62.9 & -27.3 & & & \\
\hline Technology s & & -26.3 & 49.0 & -30.5 & 22.2 & 48.5 & -4.2 \\
\hline Technology s & e 2 & -12.7 & 24.5 & -27.2 & 18.0 & 52.3 & 0.5 \\
\hline Sectoral share & 1 & 38.7 & 13.9 & 3.2 & -20.2 & -11.8 & 12.4 \\
\hline Sectoral share & 2 & 25.0 & 38.5 & -0.2 & -16.1 & -15.6 & 7.7 \\
\hline
\end{tabular}

\begin{tabular}{|c|c|c|c|c|c|c|}
\hline \multicolumn{7}{|c|}{$1951-1961$} \\
\hline Total change \% & 11.5 & -33.2 & 56.6 & -41.3 & -22.7 & -11.0 \\
\hline Technology share 1 & -132.4 & -46.4 & 47.0 & -28.5 & -5.7 & -11.8 \\
\hline Technology share 2 & -7.1 & -43.7 & 52.9 & -38.7 & -12.3 & -11.3 \\
\hline Sectoral share & 144.0 & 13.2 & 9.6 & -12.9 & -17.0 & 0.9 \\
\hline Sectoral share & 18.6 & 10.5 & 3.7 & -2.7 & -10.4 & 0.4 \\
\hline
\end{tabular}

\section{A general assessment}

Widening disparities in incomes and employment opportunities have been traced to biased technical change and sectoral change, possibly linked to changing trade 
patterns, as discussed by Freeman(1995) and Berman et al (1994). Initial concentration on the U.S.A. has been extended to other countries by Berman et al(1998) and Machin and Van Reenen (1998) and the origins of these changes traced to much earlier developments by Goldin and Katz (1998). This note has considered developments in what was once the leading manufacturing nation and one of the most open economies in the world. The principal conclusions, which emerge from a detailed consideration of skill changes for both men and women over forty years, are:

(i) There has been a strong shift away from manual towards non-manual work over this period, for both men and women.

(ii) There have also been shifts between skill categories within each of these groups and these have varied over time. It is important to disaggregate manual and non-manual groups into different skill categories.

(iii) Both sectoral and technological change are important for all groups, in all periods but the balance between their relative importance varies between occupational groups and over time. There is no evidence of a general increase in either sectoral or technology effects over time, although movements against manual workers have accelerated since 1971.

\section{References}

Berman, Eli, John Bound and Zvi Griliches (1994). 'Changes in the Demand for Skilled Labour Within U.S. Manufacturing Industries: Evidence from the Annual Survey of Manufacturing', Quarterly Journal of Economics, CIX, 367 - 397.

Berman, Eli, John Bound and Stephen Machin (1998) 'Implications of skill-biased technological change; international evidence' Quarterly Journal of Economics, CXIII, $1245-1279$. 
Goldin, Claudia and Lawrence Katz (1998). 'The origins of technology - skill complementarity', Quarterly Journal of Economics, CXIII, 693 -732

Machin, Stephen and John Van Reenen (1998). 'Technology and changes in skill structure: evidence from seven OECD countries', Quarterly Journal of Economics, CXIII, $1215-1244$. 